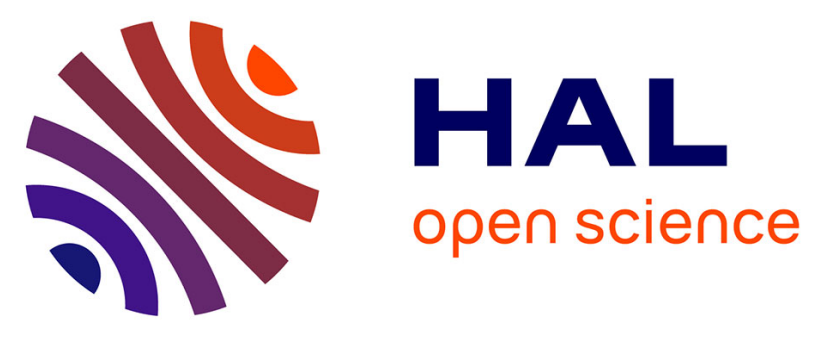

\title{
Radiobiological optimization comparison between pulse-dose-rate and high-dose-rate brachytherapy in patients with locally advanced cervical cancer
}

Pierre Annede, Isabelle Dumas, Antoine Schernberg, Anne Tailleur, Ingrid Fumagalli, Sophie Bockel, Fabien Mignot, Manon Kissel, Eric Deutsch, Christine Haie-Meder, et al.

\section{To cite this version:}

Pierre Annede, Isabelle Dumas, Antoine Schernberg, Anne Tailleur, Ingrid Fumagalli, et al.. Radiobiological optimization comparison between pulse-dose-rate and high-dose-rate brachytherapy in patients with locally advanced cervical cancer. Brachytherapy, 2019, 18, pp.370 - 377. 10.1016/j.brachy.2018.12.009 . hal-03486383

\section{HAL Id: hal-03486383 https://hal.science/hal-03486383}

Submitted on 20 Dec 2021

HAL is a multi-disciplinary open access archive for the deposit and dissemination of scientific research documents, whether they are published or not. The documents may come from teaching and research institutions in France or abroad, or from public or private research centers.
L'archive ouverte pluridisciplinaire HAL, est destinée au dépôt et à la diffusion de documents scientifiques de niveau recherche, publiés ou non, émanant des établissements d'enseignement et de recherche français ou étrangers, des laboratoires publics ou privés.

\section{(ㄷ)(1) $\$$}

Distributed under a Creative Commons Attribution - NonCommerciall 4.0 International 
1 Radiobiological optimization comparison between pulse-dose rate and high-

2

3

4

5

6

7

8

9

10

11

12 dose rate brachytherapy in locally advanced cervical cancer patients

Pierre ANNEDE, MD, MSc ${ }^{1}$, pierreannede@gmail.com ;

Isabelle DUMAS, PhD ${ }^{1}$, Isabelle.DUMAS@gustaveroussy.fr ;

Antoine SCHERNBERG, MD, MSc ${ }^{1,2}$ Antoine.SCHERNBERG@gustaveroussy.fr ;

Anne TAILLEUR ${ }^{1}$, Anne.TAILLEUR@gustaveroussy.fr ;

Ingrid FUMAGALLI, MD, MSc ${ }^{1}$, Ingrid.FUMAGALLI@gustaveroussy.fr ;

Sophie BOCKEL, MD, MSc ${ }^{1}$, Sophie.BOCKEL@gustaveroussy.fr ;

Fabien MIGNOT, MD, MSc ${ }^{1}$, Fabien.MIGNOT@gustaveroussy.fr ;

Manon KISSEL, MD ${ }^{1}$, MANON.KISSEL@gustaveroussy.fr ;

Eric DEUTSCH, MD, PhD ${ }^{1,2}$, Eric.DEUTSCH@gustaveroussy.fr ;

Christine HAIE-MEDER, MD ${ }^{1}$, Christine.HAIEMEDER@gustaveroussy.fr ;

Cyrus CHARGARI, MD, PhD ${ }^{1,2,4,5}$, Cyrus.CHARGARI@gustaveroussy.fr

1 Radiotherapy department, Brachytherapy Unit, Gustave Roussy Cancer Campus, Villejuif, France 2 INSERM U1030, Gustave Roussy Cancer Campus, Villejuif France 3 Faculté de médecine PARIS Sud, université Paris Sud, Université Paris Saclay 4 French Military Health Services Academy, Ecole du Val-de-Grâce, Paris, France 5 Institut de Recherche Biomédicale des Armées, Bretigny-sur-Orge, France

\section{Corresponding author}

Cyrus CHARGARI, MD, PhD;

Radiation Oncology Department Brachytherapy Unit

Gustave Roussy Cancer Campus

114 rue Edouard Vaillant, 94800,

Villejuif France

+33.1.42.11.45.66;

Email: cyrus.chargari@gustaveroussy.fr 


\section{Abstract}

Objective: Only scarce data are available on the possibility to include radiobiological optimization as part of the dosimetric process in cervical cancer treated with brachytherapy (BT). We compared dosimetric outcomes of pulse-dose rate (PDR) and high-dose rate (HDR)-BT, according to linear quadratic model (LQM).

Methods: 3D dosimetric data of 10 consecutive patients with cervical cancer undergoing intracavitary image-guided adaptive PDR-BT after external beam radiation therapy (EBRT) were examined. A new HDR plan was generated for each patient using the same method as for the PDR plan. The procedure was intended to achieve the same $\mathrm{D}_{90} \mathrm{CTV}_{\mathrm{HR}}$ with HDR as with PDR planning after conversion into dose equivalent per $2 \mathrm{~Gy}$-fractions (EQD2) following LQM. Plans were compared for dosimetric variables.

Results: As per study's methodology, the $\mathrm{D}_{90} \mathrm{CTV}_{\mathrm{HR}}$ was strictly identical between PDR and HDR plans: 91.0 Gy (Interquartile: 86.0-94.6 Gy). The median $\mathrm{D}_{98} \mathrm{CTV}_{\mathrm{IR}}$ was $62.9 \mathrm{GV}_{\mathrm{EQD2}}$ with HDR, versus 65.0 $\mathrm{Gy}_{\mathrm{EQD2} 2}$ with PDR ( $\mathrm{p}<0.001$ ). The median bladder $\mathrm{D}_{2 \mathrm{cc}}$ was $65.6 \mathrm{~Gy}_{\mathrm{EQD2}}$ with $\mathrm{HDR}$, versus $62 \mathrm{~Gy}_{\mathrm{EQD2}}$ with PDR ( $p=0.004)$. Doses to the rectum, sigmoid and small bowel were higher with HDR plans with a median $\mathrm{D}_{2 \mathrm{CC}}$ of 55.6 $\mathrm{Gy}_{\mathrm{EQD} 2}$ (versus 55.1 $\mathrm{Gy}_{\mathrm{EQD} 2}, \mathrm{p}=0.027$ ), 67.2 $\mathrm{Gy}_{\mathrm{EQD2}}$ (versus $\mathrm{S} 64.7 \mathrm{~Gy}_{\mathrm{EQD} 2}, \mathrm{p}=0.002$ ) and $69.4 \mathrm{~Gy}_{\mathrm{EQD2}}$ (versus $66.8 \mathrm{~Gy}_{\mathrm{EQD} 2}, \mathrm{p}=0.014$ ) respectively. For organs at risk (OARs), the effect of radiobiological weighting depended on the dose delivered. When OARs BT contribution to $D_{2 c c}$ doses was <20 Gy $\mathrm{EQD2}_{\mathrm{E} 2}$, both $\mathrm{BT}$ modalities were equivalent. OARs EQD2 doses were all higher with HDR when $\mathrm{BT}$ contribution to $\mathrm{D}_{2 \mathrm{cc}}$ was $\geq 20 \mathrm{G} \mathrm{y}_{\mathrm{EQD} 2}$.

Conclusion: Both BT modalities provided satisfactory target volume coverage with a slightly higher value with the HDR technique for OARs $D 2_{c c}$ while $C T V_{\mathbb{R}}$ received higher dose in the PDR plan. The radiobiological benefit of PDR over HDR was predominant when BT contribution dose to OARs was > $20 G y$.

Keywords: linear quadratic model; pulse dose rate brachytherapy; high dose rate brachytherapy; cervical cancer; radiobiological effect. 


\section{Background}

68

Intracavitary brachytherapy (BT) delivered after concurrent chemoradiation plays a major role in the treatment of locally advanced cervical cancer (LACC) and represents the standard of care (1). To date the diverse treatment approaches derived from historical BT schools (e.g. Manchester, Paris, Stockholm) still dominate the basic dosimetric principles. In addition, many new developments such as new applicators, image-guided adaptive BT (IGABT) and the high-dose (HDR) and pulse-dose rate (PDR) remote control afterloading systems, have contributed further to increase optimization capabilities.

HDR brachytherapy was initiated in the late 1950s with ${ }_{60} \mathrm{Co}$ and has been increasingly used for the treatment of LACC. Currently, HDR is widely used instead of low-dose rate (LDR) and has substantial advantages in terms of physics properties and convenience (dose optimization, radiation safety, and short treatment time). Radiobiologically, LDR is considered advantageous over HDR in terms of late tissue effects, although not reflected in randomized trials reporting that probabilities of local control and overall survival were similar for LDR and HDR treatments (2-5). However, those trials have been criticized for a number of methodologic limitations (patients and tumors heterogeneity, utilization of different radiation techniques, follow-up limitations) (6). In a randomized comparison of two LDR dose rates (0.4 versus $0.8 \mathrm{~Gy} / \mathrm{h}$ ), prevalence of complications over time was increased in the higher dose rate group, without difference in terms of local control, confirming that dose rate had a differential impact between tumor and normal tissue response (7).

PDR-BT was developed in the 1990s, theoretically combining physical advantages of HDR and radiobiological advantages of LDR brachytherapy. With PDR-BT, instead of delivering the dose continuously as in LDR, a series of continuous hourly pulses is delivered, few minutes each hour. Typically, the overall dose and treatment time are the same as corresponding LDR schedule. PDR compared to LDR has many specific advantages such as isodose optimization capability, better therapeutic ratio attributed to multiple fractionation regimens leading to cell cycle redistribution, as well as excellent radiation protection(8,9). From a logistic point of view, the main disadvantage of the PDR compared to HDR is the need for a dedicated hospital room equipped with a remote afterloading system. Therefore the possible number of BT procedures that can be performed daily is limited. On the other hand, the number of applications is reduced.

To date, only scarce data are available on the possibility to include radiobiological optimization as part of the dosimetric process, although this strategy has been pointed out in the last International Commission on Radiation Units and Measurements (ICRU) guidelines dedicated to BT 
(10). The aim of this study was to explore the radiobiological impact of BT modality on dosimetric outcomes, according to linear quadratic model (LQM).

\title{
Methods
}

\section{Patient population}

\begin{abstract}
Clinical and dosimetric data of ten consecutive patients receiving intracavitary image-guided adaptive BT after pelvic external beam radiation therapy (EBRT) and concomitant chemotherapy in 2016 for a LACC were examined. Only patients with NO disease after an exhaustive pre-treatment workup were included to overcome the issue of potential contribution of simultaneaous lymph node boosts.
\end{abstract}

The EBRT radiation procedure has been reported in detail before (11). Briefly, all patients received a pelvic EBRT, with a normal fractionation delivering 45 Gy in 25 daily fractions over 5 weeks, delivered through intensity modulated radiotherapy (Helical TomoTherapy ${ }^{\circledR}$, Accuray, California).

\section{Linear-quadratic model}

For radiobiological weighting, the LQM for incomplete repair was used (12). As an input for the model, the GEC-ESTRO (Groupe Européen de Curiethérapie - European Society for Radiotherapy \& Oncology) recommendations suggest a uniform value of alpha/Beta ratio $(\alpha / \beta)=10 \mathrm{~Gy}$ for tumour and clinical target volume (CTV) and $\alpha / \beta=3$ Gy for all OARs. The modelling of PDR requires a value for the half time of tissue repair $\left(T_{1 / 2}\right)$, although $T_{1 / 2}$ is not as consolidated as the previous biological parameters, the GEC-ESTRO refers that $1.5 \mathrm{~h}$ is the "best estimate" for this parameter, therefore this value was used for all tissues involved. With these parameters, the biological equivalent dose in 2-Gy fractions EBRT (EQD2) was calculated (12). Cumulative dose volume histograms (DVH) were generated, by adding the contribution of EBRT ( 45 Gy in 25 fractions) with that of BT.

\section{PDR BT procedure}

The implantation technique description is available in a previous publication (11). After the implantation, based on the vaginal mould applicator technique, a pelvic MRI was acquired, with T2 
sagittal, axial, and coronal sequences, which were transferred to BrachyVision (Varian Medical Systems, Palo Alto) platforms in order to perform contouring of the gross target volume (GTV), high risk CTV $\left(\mathrm{CTV}_{\mathrm{HR}}\right)$, intermediate risk $\mathrm{CTV}\left(\mathrm{CTV}_{\mathrm{IR}}\right)$ and organs at risk (OAR) according to European recommendations from the GEC-ESTRO (12). The planning process started with an activation of the dwell positions in regard to the $\mathrm{CTV}_{\mathrm{IR}}$, and a standard physical dose of $15 \mathrm{~Gy}$ in 30 pulses of $0.5 \mathrm{~Gy}$ (corresponding to an EQD2 dose of $15 \mathrm{~Gy}_{\mathrm{EQD} 2}$ according to LQM) was prescribed and normalized to Point $A$. The optimization process was aimed at achieving the following planning objectives: $D_{90}$ (minimum dose delivered to $90 \%$ of the volume) to the $\mathrm{CTV}_{\mathrm{HR}} \geq 85 \mathrm{GY}_{\mathrm{EQD2}}, \mathrm{D}_{98} \mathrm{CTV}_{\mathrm{IR}} \geq 60 \mathrm{~Gy}_{\mathrm{EQD} 2}, \mathrm{D}_{2 \mathrm{cc}}$ (minimum dose delivered to most exposed $2 \mathrm{cc}$ ) of the bladder $\leq 85 \mathrm{~Gy}_{\mathrm{EQD2}}, \mathrm{D}_{2 \mathrm{cc}}$ of the rectum and sigmoid $\leq 75 \mathrm{~Gy}_{\mathrm{EQD2} 2}$. Dwell times and positions were adjusted manually by the same pair of radiation oncologist and physicist, in an iterative way until DVH constraints were fulfilled as best as possible.

\section{Conversion to HDR planning treatment}

A new Iridium 192 HDR dosimetry was performed for each patient using the same image set than for the PDR plan. In the same way, the treatment planning process started with an activation of the same dwell positions as in the PDR planning treatment. A standard physical dose of $13.48 \mathrm{~Gy}$ in four fractions of $3.37 \mathrm{~Gy}$ (corresponding to an EQD2 dose of $15 \mathrm{GyE}_{\mathrm{QD2} 2}$ according to LQM) was prescribed and normalized to point $A$. Then, the dwell time for each dwell position was optimized manually in an iterative way following the same pattern as for the PDR optimization. The procedure aimed to reach the same coverage of $\mathrm{D}_{90} \mathrm{CTV}_{\mathrm{HR}}$ than in the PDR plan with a margin of error $\leq 0.1 \mathrm{~Gy}$.

\section{Data extraction and statistics}

PDR and HDR plan were compared using dosimetric variables for the CTVs and OAR. CTV metrics included $\mathrm{D}_{90} C T V_{\mathrm{HR}}$ (control variable) and $\mathrm{D}_{98} \mathrm{CTV}_{\mathrm{IR}}$. OAR metrics included $\mathrm{D}_{2 c c}$ of the bladder, rectum, sigmoid and small bowel. Differences in dosimetric variables were evaluated for statistical significance $(p<0.05)$ using the two-tailed Student's paired t-test. Prior to application of the Student's t-test, the data were verified to be normally distributed using a Shapiro-Wilk test.

Finally, the double ratio EQD2 $2_{\mathrm{RECTUM}} / E Q D 2_{\mathrm{CTVHR}}$ (derived from the $\mathrm{BED}_{\mathrm{NT}} / \mathrm{BED}_{\mathrm{TUM}}$ ratio described by Sminia et al.), was applied as a function of the overall BT duration in PDR plan, which is directly correlated to the number of pulses and inversely correlated to the dose per pulse (13). This 
162

163

164

165

166

167

168

169

170

171

172

173

174

175

176

177

178

179

180

181

182

183

184

185

186

187

188

189

190

191

192

double ratio represents the therapeutic ratio of HDR relative to PDR depending of the dose per pulse applied in the PDR plan:

$\mathrm{HDR} / \mathrm{PDR}$ therapeutic ratio $=$

Data management and statistical analyses were performed using R 3.4.1 software (The R Foundation for Statistical Computing Platform, Vienna, Austria).

\section{Results}

\section{Patients and EBRT dose contribution}

Data from 10 patients treated with endocavitary BT only were analysed. Tumor FIGO stages were as follows: 2 stage IB2, 6 stage III, 1 stage IIIA and 1 stage IIIB. Tumor involved the lower third of vagina in 2 patients; the middle and the upper third of the vagina were involved in two patients.

Regarding pelvic EBRT, for all patients, dose delivered to the planning target volume (PTV) was $45 \mathrm{~Gy}$ with dose per fraction of $1.8 \mathrm{~Gy}$. Following ICRU guidelines (10), the contribution of EBRT to CTV and OAR metrics assessed in BT plan were therefore considered equal to $44.3 \mathrm{~Gy}_{\text {EQD2 }}$ and 43.2 $\mathrm{Gy}_{\mathrm{EQD} 2}$ respectively (all doses in 2-Gy equivalents, applying the linear quadratic model with a $\mathrm{a} / \mathrm{\beta}$ ratio of 10 for CTVs and 3 for OAR). Dosimetric data for both treatment modalities are listed in Table 1.

\section{PDR BT}

Median number of pulses was 50 (interquartile range (IQR), 47-53). The aforementioned planning aims for $\mathrm{CTV}_{\mathrm{HR}}$ were reached for seven patients. Among the three others, two were very close with a $\mathrm{D}_{90} \mathrm{CTV}_{\mathrm{HR}}$ of $84.4 \mathrm{~Gy}_{\mathrm{EQD} 2}$ and $84.0 \mathrm{~Gy}_{\mathrm{EQD} 2}$ respectively. The median $\mathrm{D}_{90} \mathrm{CTV} \mathrm{HR}_{\mathrm{HR}}$ and $\mathrm{D}_{98} \mathrm{CTV}_{\mathrm{IR}}$ were 91.0 $\mathrm{Gy}_{\mathrm{EQD2}}\left(\mathrm{IQR}, 86.0-94.6 \mathrm{~Gy}_{\mathrm{EQD2}}\right.$ ) and 65.0 $\mathrm{Gy}_{\mathrm{EQD2}}\left(\mathrm{IQR}, 62.9-65.5 \mathrm{~Gy}_{\mathrm{EQD2}}\right.$ ) respectively. Planning aims for OAR were reached for every patient. The median $D_{2 c c}$ of bladder, rectum, sigmoid and small bowel were $62 \mathrm{~Gy}_{\text {EQD2 }}\left(\mathrm{IQR}, 58.8-70.2 \mathrm{~Gy}_{\text {EQD2 } 2}\right.$ ), 55.1 Gy 56.0-67.7 $\left.\mathrm{Gy}_{\mathrm{EQD2}}\right)$ and 66.8 $\mathrm{Gy}_{\mathrm{EQD2}}\left(\mathrm{IQR}, 59.2-75.9 \mathrm{~Gy}_{\mathrm{EQD2} 2}\right)$, respectively.

\section{HDR BT}

According to the study's methodology, the $\mathrm{D}_{90} \mathrm{CTV}_{\mathrm{HR}}$ coverage was strictly identical to that of obtained with PDR plan. The $\mathrm{CTV}_{\mathbb{I R}}$ coverage was lower with HDR-BT for all patients. The median 
$\mathrm{D}_{98} \mathrm{CTV}_{\mathrm{IR}}$ was $62.9 \mathrm{GY}_{\mathrm{EQD2}}$ (versus $65.0 \mathrm{GY}_{\mathrm{EQD2}}$ with $\mathrm{PDR}, \mathrm{p}<0.001$ ). Conversely, dose to the bladder was increased with HDR-BT for all patients. The median bladder $\mathrm{D}_{2 \mathrm{cc}}$ was $65.6 \mathrm{~Gy}_{\mathrm{EQD} 2}$ (versus $62 \mathrm{~Gy}_{\mathrm{EQD} 2 \text {, }}$ $\mathrm{p}=0.004)$. Doses to the rectum, sigmoid and small bowel were higher in 7,9 and 8 cases with a median $\mathrm{D}_{2 \mathrm{cc}}$ of $55.6 \mathrm{~Gy}_{\mathrm{EQD2}}$ (versus $55.1 \mathrm{~Gy}_{\mathrm{EQD2}}, \mathrm{p}=0.027$ ), $67.2 \mathrm{~Gy}_{\mathrm{EQD2}}$ (versus $64.7 \mathrm{~Gy}_{\mathrm{EQD} 2}, \mathrm{p}=0.002$ ) and 69.4 $\mathrm{Gy}_{\mathrm{EQD2}}$ (versus $66.8 \mathrm{~Gy}_{\mathrm{EQD} 2}, \mathrm{p}=0.014$ ) respectively.

\section{Linear quadratic model effect}

As shown in Figure 1 the impact of the LQM was different according to the dose level and the alpha/beta ratio value considered.

Regarding the target volumes $(\alpha / \beta$ ratio $=10 \mathrm{~Gy})$, at same physical dose, EQD2 $\mathrm{D}_{90} \mathrm{CTV}_{\mathrm{HR}}$ was higher for HDR dosimetry, as compared to PDR. To adjust both plans on radiobiologically weighted $\mathrm{D}_{90} \mathrm{CTV}_{\mathrm{HR}}$, the HDR physical dose had to be decreased. Therefore, the physical dose delivered to $98 \%$ of the $C T V_{\mathbb{I}}$ was also decreased in the same range. Consequently, for two plans achieving the same EQD2 $D_{90} C_{T V}$ HR the EQD2 $D_{98} C_{T V}$ IR was lower for HDR plan, as a result of radiobiological weighting in this era receiving lower doses. This effect is shown in Figure 2.

Regarding the OAR ( $\alpha / \beta$ ratio = $3 \mathrm{~Gy}$ ), lowering the HDR physical dose to adjust both plans on radiobiologically weighted $\mathrm{D}_{90} C T \mathrm{~V}_{\mathrm{HR}}$ led to decrease the EQD2, and the extent of decrease depended on the BT contribution. When the dose contribution of BT was very low, the effect of radiobiological weighting was also low, leading to EQD2 $D_{2 c c}$ being almost equivalent for PDR and HDR dosimetry. However, when BT contribution increased, the decrease of physical dose caused by the adjustment on $\mathrm{D}_{90} \mathrm{CTV}_{\mathrm{HR}}$ did not counterbalance the radiobiological effect for HDR OARs. Thus, the EQD2 $\mathrm{D}_{2 \mathrm{cc}}$ doses calculated for OARs were always higher for HDR plan (Figure 2). Although no firm dose threshold could be identified, the effect of radiobiological weighting became obvious for BT doses $\geq$ $20 \mathrm{~Gy}_{\text {EQD2 }}$

The interaction between dose level and the LQM is summarized in Figure 3. Converting PDR dosimetry to HDR had quite a similar impact on EQD2 $\mathrm{CTV}_{\mathrm{IR}}$ for the range of doses reported in our population, decreasing the dose uniformly for all patients. For OARs, the effect of radiobiological weighting depended on the dose delivered. For implants in which BT contribution was low, schematically $D_{2 c c}<20 \mathrm{~Gy}_{\mathrm{EQD} 2}$, there was equivalence between both $\mathrm{BT}$ modalities. However, when OARs $\mathrm{D} 2_{\mathrm{cc}}$ doses were $\geq 20 \mathrm{~Gy}_{\mathrm{EQD} 2}$, conversion of PDR to HDR led to systematically increase OAR doses. 


\section{Radiobiological optimization}

227

228

229

230

231

232

233

234

235

236

237

238

239

240

241

242

243

244

245

246

247

248

249

250

251

252

253

254

255

Figure 4 shows the HDR/PDR therapeutic ratio ([EQD2 $\left.2_{\mathrm{HDR}} / E Q D 2_{\mathrm{PDR}}\right]_{\mathrm{D} 2 \mathrm{Cc}}$ rectum/[EQD2 $\left.{ }_{\mathrm{HDR}} / \mathrm{EQD2} 2_{\mathrm{PDR}}\right]_{\mathrm{D} 90} \mathrm{CTVHR}$ ) as a function of the dose per pulse in PDR treatments for an unchanged prescribed dose of 15 Gy. For illustrative purposes, only four representative patients were plotted i.e. the patient with the highest rectal dose, the one with the lowest rectal dose and two with intermediate physical $D_{2 c c}$ doses. We observed that the impact of modifying dose per pulse in PDR was dependant on the level of dose. Schematically, when rectal physical $D_{2 c c}$ was low, lowering the dose per pulse in PDR (increasing total number of pulses) was not associated with an expected therapeutic gain. Contrariwise, the differential effect associated with dose per pulse reduction was significant when the physical dose level increased. This observation was particularly substantial when PDR physical dose to the rectal $D_{2 c c}$ exceeded $20 \mathrm{~Gy}$.

\section{Discussion}

Most studies comparing radiobiology of HDR versus LDR found a better therapeutic ratio in favour of LDR (14-16). Although there is a theoretical risk of increased complications with HDR compared to LDR, this has not been seen in properly randomized trials or meta-analysis $(2,4,17,18)$. The main explanation is that HDR-BT offers the possibility to optimize by adjusting dwell times and positions, counterbalancing its radiobiological disadvantage.

PDR-BT offers the possibility to combine the radiobiological advantage of LDR and isodose optimization, as allowed by HDR-BT. Indeed, it was published from radiobiological studies that PDR appeared to be functionally equivalent to a continuous irradiation regimen, for both early and late effects (19). However, to our knowledge PDR-BT and HDR-BT have not been compared properly in radiobiological studies. The theoretical benefit of PDR, if any, should theoretically vary according to several factors such as dose rate or tissue's characteristics (half-time repair, $\alpha / \beta$ ratio) $(19,20)$.

In the scientific literature there are very few data available comparing PDR-BT and HDR-BT. The only randomized prospective study was conducted by Kumar et al. on 37 patients with locally advanced carcinoma of cervix (9). Patients were randomized to receive either HDR (7 Gy each in three fractions, repeated weekly) or PDR (70 cGy hourly pulses for 39 hours, total 27 Gy) BT after EBRT. Toxicity rate did not differ significantly in this low power study although a trend in favour of PDR was observed. In the PDR arm, the rate of late rectal toxicity grade $\geq 2$ was $21.1 \%$ (vs. $16.7 \%$ in 
HDR) and $0 \%$ (vs.10.5\%) for grade $\geq 3$, the rate of late bladder toxicities grade $\geq 2$ was $0 \%$ (vs. 10.5\%), and the rate of late vaginal toxicities grade $\geq 2$ was $5.6 \%$ (vs. 15.8\%). The four-year disease-free survival rate was $67.1 \%$ vs. $71.8 \%(p=0.195)$.

Enrolment of patients in large clinical trials comparing both PDR and HDR-BT does not seem feasible or even relevant. The prospective EMBRACE study has included approximately one third of patients treated with PDR-BT. This large study may provide further insights into the dose rate effect in patients treated according to modern standards of IGABT based on dose optimization. However, neither large randomized study nor dosimetric comparison of both BT modalities exists, and it is therefore still difficult to anticipate which patients may get benefit from PDR or from HDR. Our findings suggest a slight difference between HDR and PDR when plans were adjusted on $\mathrm{D}_{90} \mathrm{CTV}_{\mathrm{HR}}$. Both techniques provided acceptable target volume coverage with a slightly higher value with the HDR technique for OAR $D_{2 c c}$ while $C T V_{\mathbb{I R}}$ received higher dose in the PDR plan. The theoretical radiobiological benefit of PDR over HDR became predominant when doses to OARs were superior to $20 \mathrm{GY}_{\mathrm{EQD} 2}$, although no firm dose threshold could be identified. We found that above this range of dose, the higher the dose, the greater the difference between both BT modalities (Figure 3). Similarly, the effect of adjusting both plans on radiobiologically weighted $\mathrm{D}_{90} \mathrm{CTV} \mathrm{V}_{\mathrm{HR}}$ led to clinically relevant differences in term of bladder EQD2 $D_{2 c c}$, but had only marginal effect in terms of rectal EQD2 $D_{2 c c}$, which is in line with the fact that higher physical doses delivered to the bladder (Figure $\mathbf{1}$ ).

Although PDR use is decreasing worldwide, it is still being proposed in several large institutions, and its radiobiological advantages are consensual for treatment of highly sensitive area, such as anal canal, penile glans, vagina, oral mucosa, or in paediatrics indications $(21,22)$. The results of this study provide new insights to guide future study searching for LACC patients who could benefit from PDR-BT versus HDR-BT, notably those with significant exposure to OARs and those with large $\mathrm{CTV}_{\mathrm{IR}}$. Indeed, according to our results most of patients had an equivalent dosimetry whatever the BT modality. The possibility to perform virtual pre-planning for IGABT applications has been reported in the literature (23). A pre-selection of patients based on the expected contribution of BT to OARs and the $C T V_{\mathbb{I R}}$ volume might increase the chance to optimize the therapeutic effect in these patients through radiobiological optimization, and to give centres having both BT modalities available the possibility to decide which treatment will be the most appropriate. Next step will be to anticipate which patients may benefit more from PDR-BT than from HDR-BT, if any, based not only on the expected OARs dose but also on tumors characteristics such as the size, the $\mathrm{CTV}_{\mathrm{HR}}$ volume, or the expected contribution to lymph node dose. 
Another issue addressed in this study was the possibility to adjust dose per pulse to modify

the therapeutic ratio. In some institutions treating patients with PDR-BT, dose rate is corrected by decreasing the dose rate to the isodose prescription and increasing the total number of pulses in order to not exceed the limit of $0.6 \mathrm{~Gy} /$ hour to the OARs (11). It was hypothesized that going further in this process could be beneficial in terms of therapeutic index by allowing dose escalation based on radiobiological optimization. Our results suggest that this kind of radiobiological optimization is relevant to decrease relatively more EQD2 $D_{2 c c}$ than the $D_{90} C T V_{H R}$, and this effect was the most significant at increasing physical OAR doses. Notably, the benefit of decreasing dose per pulse was particularly important when physical BT dose contribution to rectal $D_{2 c c}$ was $>20 G y$, which would lead to a total $\mathrm{D}_{2 c \mathrm{c}}>63.2 \mathrm{~Gy}_{\mathrm{EQD} 2}\left(43.2 \mathrm{~Gy}_{\mathrm{EQD} 2} \mathrm{EBRT}+20 \mathrm{~Gy}_{\mathrm{EQD2}} \mathrm{BT}\right)$. As this is still quite a low $\mathrm{D}_{2 c c}$ dose, as compared with usual guidelines for OARs dose constraints of $70-75 \mathrm{~Gy}_{\mathrm{EQD} 2}$, our results suggest that in most cases radiobiological optimization may be relevant to achieve dose escalation (Figure 4).

This study has some limitations. Direct comparison of different BT treatment plans is quite complicated because of the heterogeneity of dose parameters for EQD2 calculation used in publications and the lack of widely accepted optimization methodology. Although there are recommendations by professional societies (12), no consensus exists regarding optimal parameters in the setting of radiobiological model since no validation study on large prospective cohort exists. Thus, the EQD2 given by radiological models cannot be considered as perfectly accurate. Furthermore, only patients with NO disease were included and therefore the contribution of simultaneous lymph node boosts to the total EQD2 dose remains to be investigated. Finally, the dosimetric results reported here may not be extrapolated identically for other applicators, or other loading patterns. However, it should be highlighted that in patients with large $\mathrm{CTV}_{\mathrm{HR}}$, the effect of radiobiological optimization might be still higher. In the EMBRACE 2 study, highly stringent dose constraints have been provided in terms of $\mathrm{CTV}_{\mathrm{HR}}$ dose objectives, as well as for OARs sparing (e.g. planning aim for rectal $\mathrm{D}_{2 c c}$ dose $<65 \mathrm{GY}_{\text {EQD2 }}$ ) (24). In the most advanced tumors or in case of poor response, such stringent objectives will be achievable only by means of a more frequent use of interstitial implantations, which were shown to give more capabilities in terms of dose escalation, without exceeding OARs dose constraints (25). Our study did not address the question of interstitial applications, and this is another limitation.

\section{Conclusion}

In conclusion, our data suggest that radiobiological optimization may have a substantial role as part of the optimization process in these very advanced tumors, either by identifying patients who 

escalation by adjustments of dose per pulse. 


\section{Declarations}

323

324 Ethics approval and consent to participate

325 Ethics approval was obtained from our Institutional Review Board and consent was waived for

326 retrospective research.

327

328 Competing interests

329 The authors declare no competing financial interest.

330

331 Funding

332 This research received no specific grant from any funding agency in the public, commercial, or not-

333 for-profit sectors.

334

335

336 
1. Green JA, Kirwan JM, Tierney JF, Symonds P, Fresco L, Collingwood M, et al. Survival and recurrence after concomitant chemotherapy and radiotherapy for cancer of the uterine cervix: a systematic review and meta-analysis. The Lancet. 2001 Sep 8;358(9284):781-6.

2. Lertsanguansinchai P, Lertbutsayanukul C, Shotelersuk K, Khorprasert C, Rojpornpradit P, Chottetanaprasith $\mathrm{T}$, et al. Phase III randomized trial comparing LDR and HDR brachytherapy in treatment of cervical carcinoma. Int J Radiat Oncol Biol Phys. 2004 Aug 1;59(5):1424-31.

3. Hareyama M, Sakata K, Oouchi A, Nagakura H, Shido M, Someya M, et al. High-dose-rate versus low-dose-rate intracavitary therapy for carcinoma of the uterine cervix: a randomized trial. Cancer. 2002 Jan 1;94(1):117-24.

4. Patel FD, Sharma SC, Negi PS, Ghoshal S, Gupta BD. Low dose rate vs. high dose rate brachytherapy in the treatment of carcinoma of the uterine cervix: a clinical trial. Int $\mathrm{J}$ Radiat Oncol Biol Phys. 1994 Jan 15;28(2):335-41.

5. Teshima $\mathrm{T}$, Inoue $\mathrm{T}$, Ikeda $\mathrm{H}$, Miyata $\mathrm{Y}$, Nishiyama $\mathrm{K}$, Inoue $\mathrm{T}$, et al. High-dose rate and lowdose rate intracavitary therapy for carcinoma of the uterine cervix. Final results of Osaka University Hospital. Cancer. 1993 Oct 15;72(8):2409-14.

6. Haie-Meder C, Kramar A, Lambin P, Lancar R, Scalliet P, Bouzy J, Gerbaulet A. Analysis of complications in a prospective randomized trial comparing two brachytherapy low dose rates in cervical carcinoma. Int J Radiat Oncol Biol Phys. 1994 Jul 30;29(5):953-60

7. Liu R, Wang $\mathrm{X}$, Tian JH, Yang $\mathrm{K}$, Wang J, Jiang $\mathrm{L}$, et al. High dose rate versus low dose rate intracavity brachytherapy for locally advanced uterine cervix cancer. Cochrane Database Syst Rev. 2014 Oct 9;(10):CD007563.

8. Brenner DJ, Schiff PB, Huang Y, Hall EJ. Pulsed-dose-rate brachytherapy: Design of convenient (daytime-only) schedules. Int J Radiat Oncol • Biol • Phys. 1997 Nov 1;39(4):809-15.

9. Kumar P, Sharma DN, Kumar S, Gandhi AK, Rath GK, Julka PK. Pulsed-dose-rate vs. highdose-rate intracavitary radiotherapy for locally advanced carcinoma of cervix: A prospective randomized study. Brachytherapy. 2016 Jun;15(3):327-32.

10. Journal of the International Commission on Radiation Units and Measurements, Volume 13, Issue 1-2, 1 April 2013, Pages 89-104

11. Castelnau-Marchand P, Chargari C, Maroun P, Dumas I, Campo ER del, Cao K, et al. Clinical outcomes of definitive chemoradiation followed by intracavitary pulsed-dose rate imageguided adaptive brachytherapy in locally advanced cervical cancer. Gynecol Oncol. 2015 Nov 1;139(2):288-94.

12. Pötter R, Haie-Meder C, Van Limbergen E, Barillot I, De Brabandere M, Dimopoulos J, et al. Recommendations from gynaecological (GYN) GEC ESTRO working group (II): concepts and terms in 3D image-based treatment planning in cervix cancer brachytherapy-3D dose 
volume parameters and aspects of 3D image-based anatomy, radiation physics, radiobiology. Radiother Oncol J Eur Soc Ther Radiol Oncol. 2006 Jan;78(1):67-77.

13. Sminia P, Schneider CJ, Fowler JF. The optimal fraction size in high-dose-rate brachytherapy: dependency on tissue repair kinetics and low-dose rate. Int J Radiat Oncol Biol Phys. 2002 Mar 1;52(3):844-9.

14. Dale RG. The use of small fraction numbers in high dose-rate gynaecological afterloading: some radiobiological considerations. Br J Radiol. 1990 Apr;63(748):290-4.

15. Brenner DJ, Huang Y, Hall EJ. Fractionated high dose-rate versus low dose-rate regimens for intracavitary brachytherapy of the cervix: equivalent regimens for combined brachytherapy and external irradiation. Int J Radiat Oncol Biol Phys. 1991 Nov;21(6):1415-23.

16. Stitt JA, Fowler JF, Thomadsen BR, Buchler DA, Paliwal BP, Kinsella TJ. High dose rate intracavitary brachytherapy for carcinoma of the cervix: the Madison system: I. Clinical and radiobiological considerations. Int J Radiat Oncol Biol Phys. 1992;24(2):335-48.

17. Shigematsu Y, Nishiyama K, Masaki N, Inoue T, Miyata Y, Ikeda H, et al. Treatment of carcinoma of the uterine cervix by remotely controlled afterloading intracavitary radiotherapy with high-dose rate: a comparative study with a low-dose rate system. Int J Radiat Oncol Biol Phys. 1983 Mar;9(3):351-6.

18. Viani GA, Manta GB, Stefano EJ, de Fendi LI. Brachytherapy for cervix cancer: low-dose rate or high-dose rate brachytherapy - a meta-analysis of clinical trials. J Exp Clin Cancer Res CR. 2009 Apr 5;28:47.

19. Brenner DJ, Hall EJ. Conditions for the equivalence of continuous to pulsed low dose rate brachytherapy. Int J Radiat Oncol Biol Phys. 1991 Jan;20(1):181-90.

20. Fowler JF, Van Limbergen EF. Biological effect of pulsed dose rate brachytherapy with stepping sources if short half-times of repair are present in tissues. Int J Radiat Oncol Biol Phys. 1997 Mar 1;37(4):877-83.

21. Chargari C, Martelli H, Guérin F, Bacorro W, de Lambert G, Escande A, Minard-Colin V, Dumas I, Deutsch E, Haie-Meder C. Pulsed-dose rate brachytherapy for pediatric bladder prostate rhabdomyosarcoma: Compliance and early clinical results. Radiother Oncol. 2017 Aug;124(2):285-29

22. Balgobind BV, Koedooder K, Ordoñez Zúñiga D, Dávila Fajardo R, Rasch CR, Pieters BR. A review of the clinical experience in pulsed dose rate brachytherapy. $\mathrm{Br} J$ Radiol. 2015;88(1055):20150310.

23. Fokdal L, Tanderup K, Hokland SB, Røhl L, Pedersen EM, Nielsen SK, Paludan M, Lindegaard JC. Clinical feasibility of combined intracavitary/interstitial brachytherapy in locally advanced cervical cancer employing MRI with a tandem/ring applicator in situ and virtual preplanning of the interstitial component. Radiother Oncol. 2013 Apr;107(1):63-8. doi: 10.1016/j.radonc.2013.01.010.

24. EMBRACE [Internet]. [cited 2018 Sep 2]. Available from: https://www.embracestudy.dk/Public/Default.aspx?main=1\&sub=3\&embrace=embrace 
25. Fokdal L, Sturdza A, Mazeron R, Haie-Meder C, Tan LT, Gillham C, et al. Image guided adaptive brachytherapy with combined intracavitary and interstitial technique improves the therapeutic ratio in locally advanced cervical cancer: Analysis from the retroEMBRACE study. Radiother Oncol. 2016;120(3):434-40. 
Table 1: Dosimetric data for target volumes and organs at risk (median with interquartile ranges).

Table 1. Dosimetry of targets volume and organs at risk (median with interquartile ranges)

\begin{tabular}{|c|c|c|c|}
\hline & PDR BT & HDR BT & $P$-value \\
\hline Target volume & & & \\
\hline D90 CTVHR(Gy) & $91.0(86.0-94.6)$ & $91.0(86.0-94.6)$ & NA \\
\hline D98 CTVR(Gy) & $65.2(62.9-65.5)$ & $62.9(60.9-63.7)$ & $<0.001$ \\
\hline Organs at risk & & & \\
\hline D2cc Bladder (Gy) & $62.9(58.8-70.2)$ & $65.6(59.7-76.3)$ & 0.004 \\
\hline D2c Rectum (Gy) & $55.1(54.3-55.6)$ & $55.6(54.5-56.3)$ & 0.027 \\
\hline D2c sigmoid (Gy) & $64.7(56.0-67.7)$ & $67.2(56.7-71.9)$ & 0.002 \\
\hline D2cc small bowel (Gy) & $66.8(59.2-75.9)$ & $69.4(59.8-85.5)$ & 0.014 \\
\hline
\end{tabular}

BT: brachytherapy; HDR high-dose rate; $D R$ low-dose rate, Dx: minimum dose delivered to x\% of the volume, Dxc: minimum dose delivered to most exposed $x c c$

Figure 1: Paired boxplot of target and normal tissue metrics following BT modality.

Figure 2: Linear quadratic model for organs at risk and target volumes.

Figure 3: Comparison of 2 Gy equivalent dose (EQD2) between high dose rate and pulse dose rate brachytherapy.

436 Each point represents a dosimetric variable for one patient. The abscissa represents the EQD2 of the

437 PDR plan while the ordinate represents the EQD2 of HDR plan. When the point is above the dashed

438 line, this means that the dose EQD2 is higher in the HDR plan.

Figure 4: Therapeutic ratio of HDR relative to PDR, according to total number of hourly pulses

441 When the ratio is superior to 1 (above the dashed line), PDR allowed a better therapeutic ratio over 442 HDR.

443 D2cc rectum indicates the physical dose to the rectum in the PDR plan. 


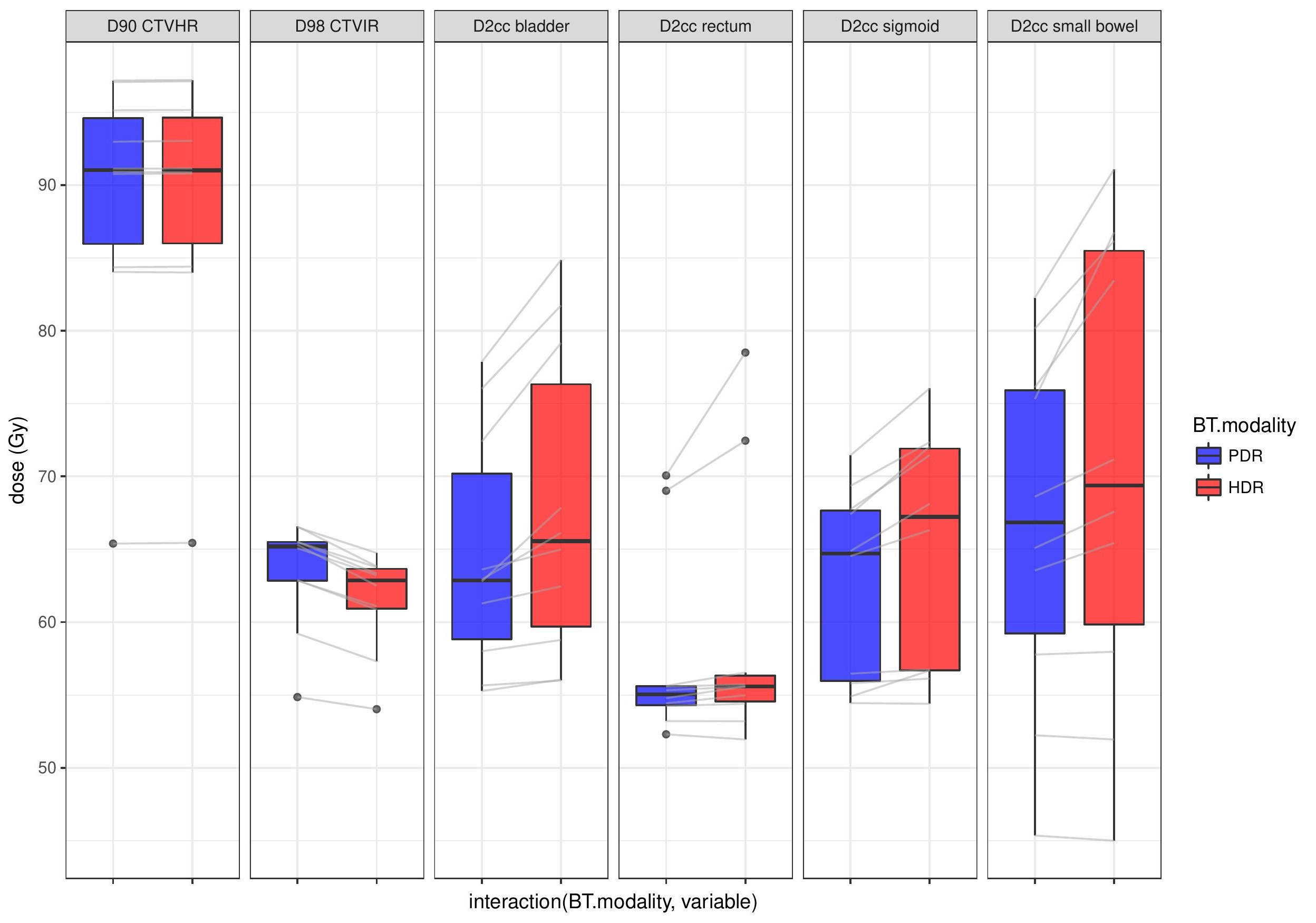



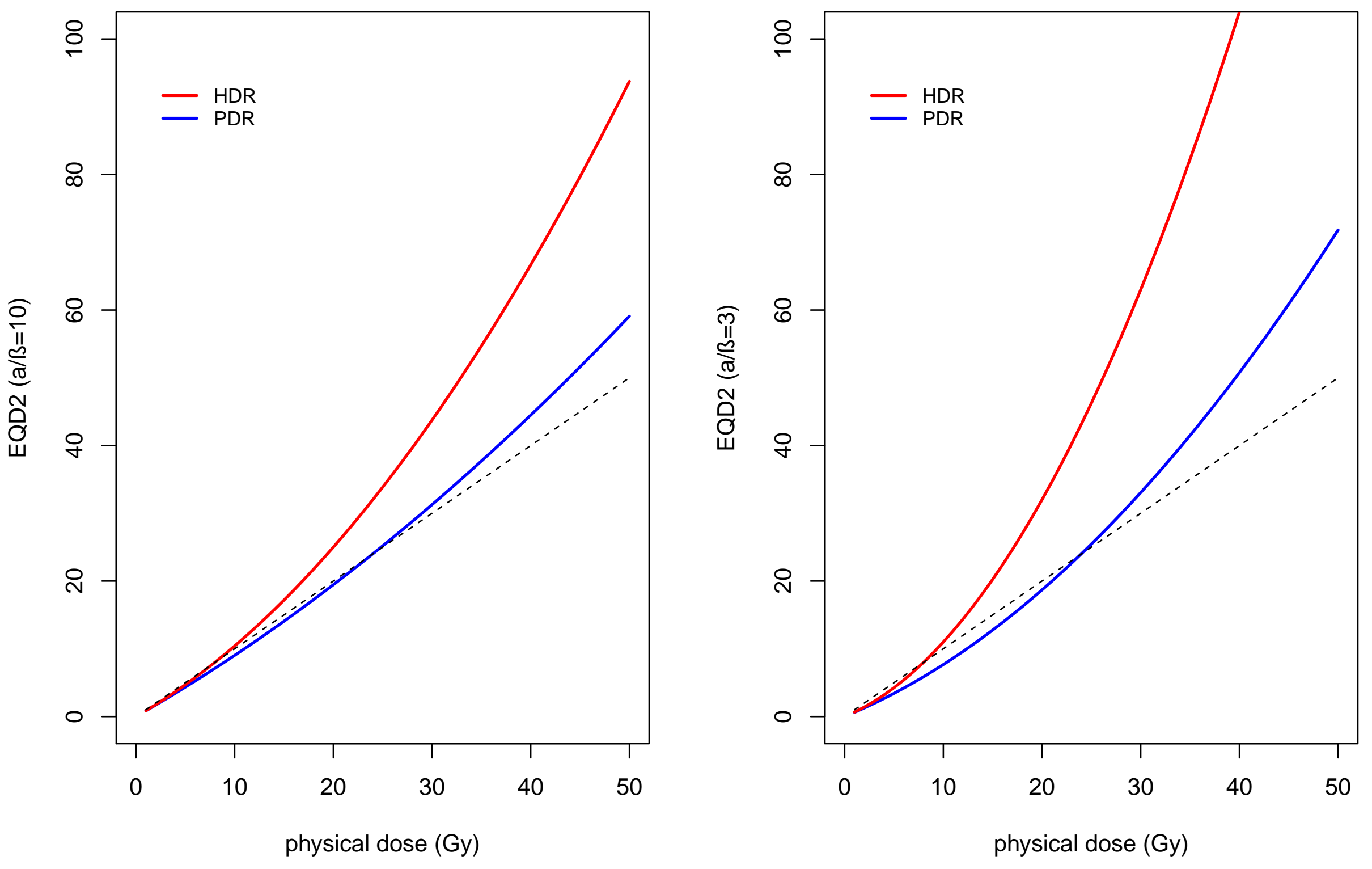

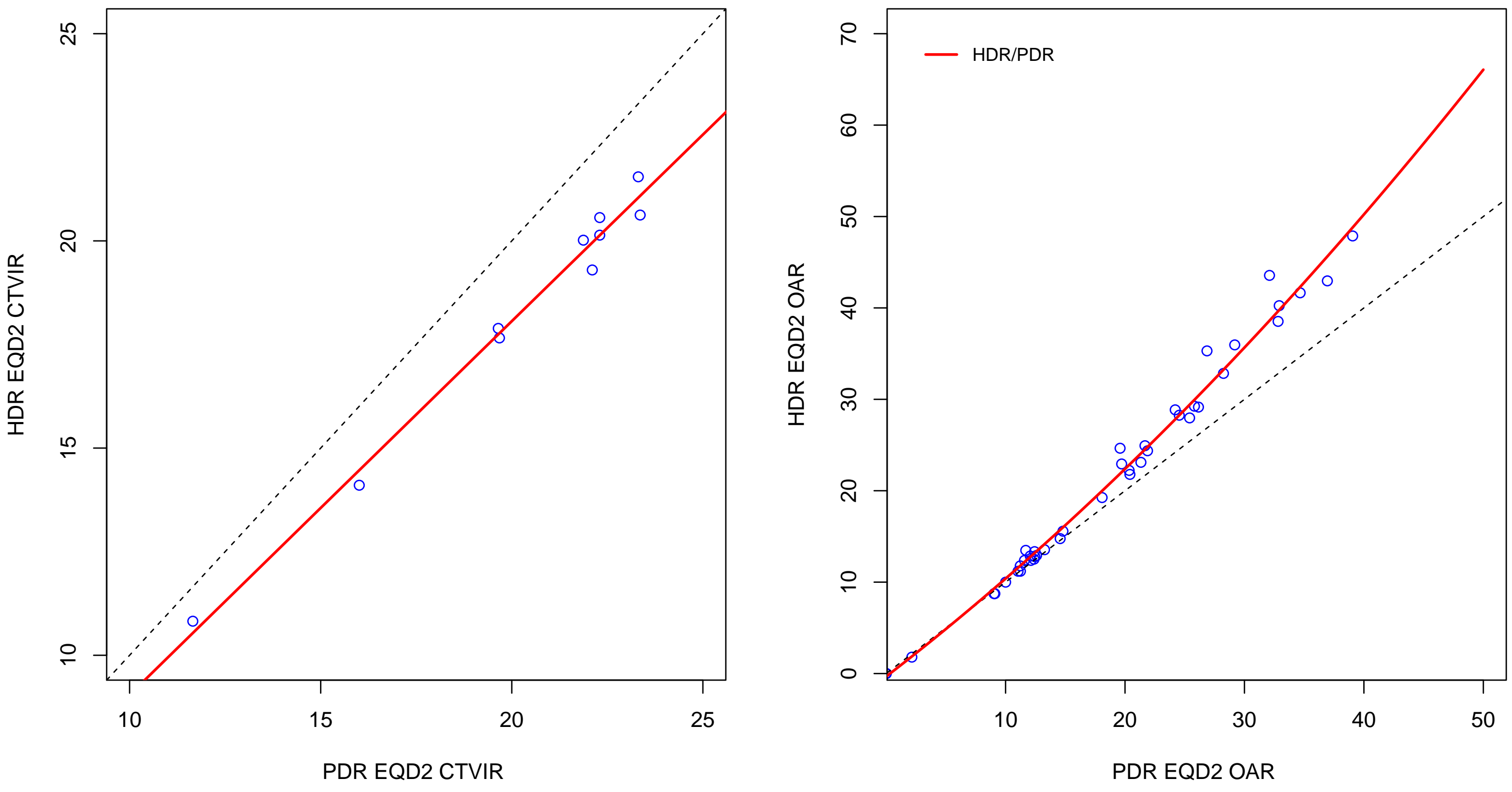


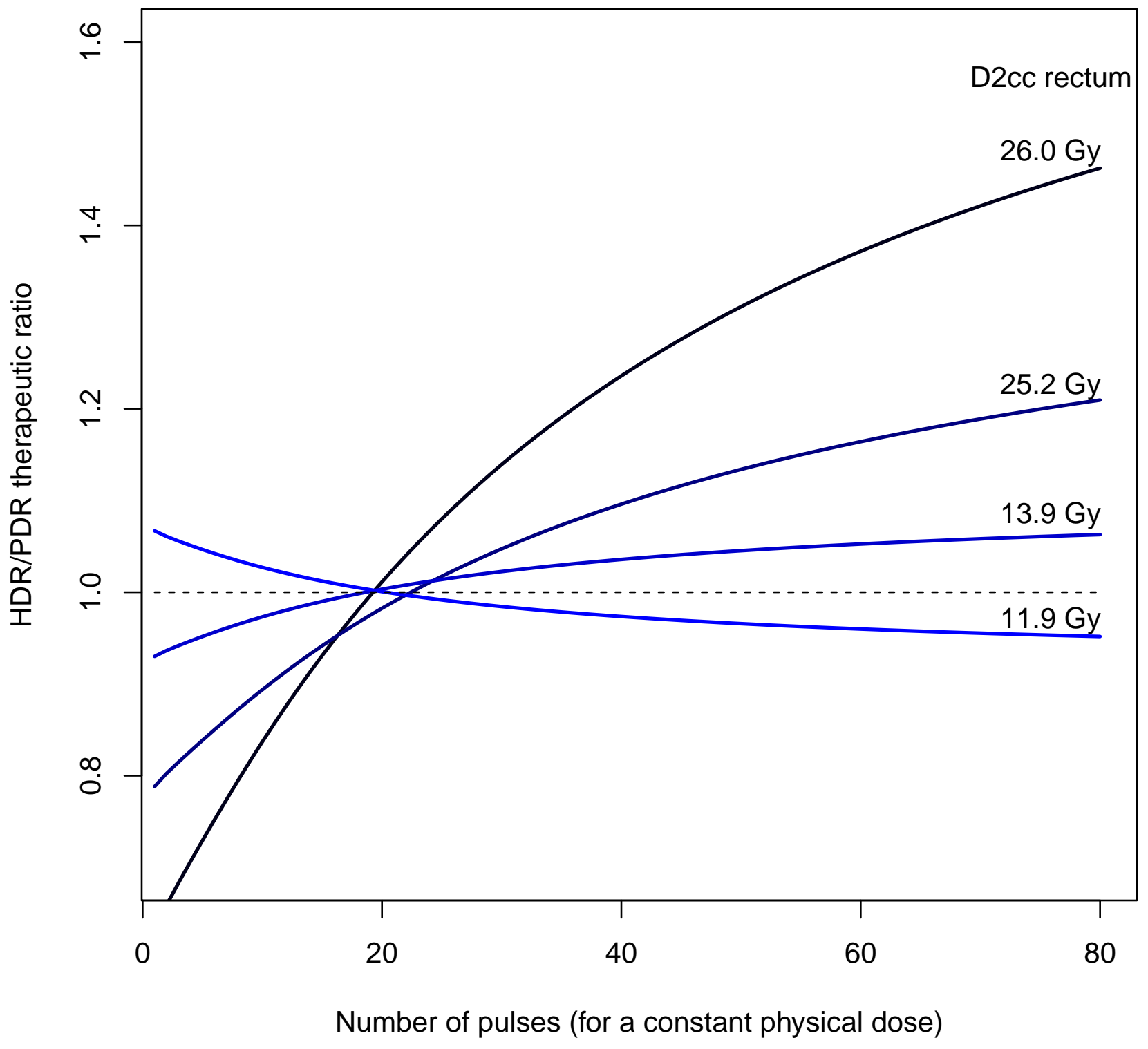

